\title{
Nachruf
}

\section{Frau Emilie Guggenheim-Schnurr}

7.Mai 1906 bis 26. Juni 1978

Frau Emilie Guggenheim-Schnurr in Basel, Ehrenmitglied unserer Gesellschaft, wurde durch ihren Mann für die Wissenschaftsgeschichte eingenommen. Ihre Beziehung zu Dr. phil. Markus Guggenheim (1885-1970) war zunächst rein beruflicher Natur : sie erfüllte jahrelang die anspruchsvolle Aufgabe einer Sekretärin bei dem temperamentvollen und eigenwilligen, durch seine Blindheit behinderten, aber in seinem Forscherdrang keineswegs gebrochenen Biochemiker. Als Dr. Guggenheims erste Frau ihr Leben vorzeitig zu Ende gehen spürte, sprach sie den Wunsch aus, Emilie Schnurr möge ihren Platz einnehmen und ihrem Mann in seinem weiteren Leben zur Seite stehen. Das hat Frau Guggenheim-Schnurr getan. Die beiden Ehegatten lebten ihr ganzes Leben gemeinsam. Zusammen besuchten sie auch Vorträge und Kongresse, u.a. die Tagungen der SGGMN. Auch nachdem ihr Mann nach mehreren von zunehmender Schwäche geprägten Leidensjahren gestorben war, folgte Frau Guggenheim gerne und aufmerksam den Mitteilungen und Diskussionen an unseren Zusammenkünften.

Im Juli 1962 errichtete das Ehepaar Guggenheim-Schnurr die unseren Mitgliedern wohlbekannte Stiftung für Geschichte der Medizin und der Naturwissenschaften, deren Zuschüsse seither den Druck manches wissenschaftsgeschichtlichen Buches ermöglicht haben. Die Stiftung erlaubt es uns ferner, jedes Jahr den Kongreß der Schweizerischen Naturforschenden Gesellschaft durch einen Vortrag zu bereichern, der ein größeres historisches Thema kompetent behandeln und gleichzeitig in seiner Bedeutung für den gegenwärtigen Naturwissenschafter und Arzt darstellen soll. Schließlich darf unsere Gesellschaft seit zehn Jahren jeweils einem jungen Kollegen den Henry-E.-Sigerist-Preis für eine besonders gute wissenschaftsgeschichtliche Dissertation verleihen. (Der erste Preisträger war 1968 Dr. med. Peter Wobmann mit einer Doktorarbeit über Albrecht von Haller als Begründer der modernen Hämodynamik.) Frau Emilie Guggenheim-Schnurr, obwohl selber seit Jahren behindert, hat noch 1977 den Stiftungsrat zu seiner jährlichen Sitzung in ihrem Haus empfangen und bewirtet und mit den andern Ratsmitgliedern für die möglichst sinnvolle Verwendung des Geldes gesorgt. Die Dr.-Markus-Guggenheim-Schnurr-Stiftung für Geschichte der Medizin und der Naturwissenschaften bleibt uns als Denkmal dieses vorbildlichen Ehepaares erhalten, und in Dankbarkeit werden wir auch in Zukunft an Emilie Guggenheim und ihren Mann denken.

Huldrych M. Koelbing

Präsident der SGGMN 